\title{
Karyology of four Indian snakes
}

\author{
Sharma * Om Parkash and Gurpreet Kour ** \\ Department of Zoology, University of Jammu, J\&K- 180006 (India)
}

\begin{abstract}
Cytogenetic studies were carried out on four species of Indian snakes viz Eryx conicus (Family Boidae), Naja naja naja (Family Elapidae), Vipera russelli and Echis carinatus (Family Viperidae) collected from Jammu region (J\&K). Both E. conicus and N. n. naja show deviation from typical ophidian karyotype (2n=36), having 2n=34 (16 macro- and 18 microchromosomes, $\mathrm{NF}=42$ ) in E. conicus and $2 \mathrm{n}=38$ (16 macro- and 22 microchromosomes and $\mathrm{NF}=50)$ in $N$. n. naja. In both the species sex chromosomes are undifferentiated. V. russelli and E. carinatus exhibited typical ophidian karyotype viz $2 \mathrm{n}=36$ ( 16 macro- and 20 microchromosomes) with $\mathrm{NF}=48$ and 50 respectively. They possess a well differentiated ' $\mathrm{ZW}$ ' sex mechanism in female, where 'W' is smaller and submetacentric, a final step in the evolution of sex chromosome in snakes and ' $\mathrm{Z}$ ' is larger and metacentric.
\end{abstract}

Key Words: Boidae, Cytogenetics, Elapidae, Microchromosomes, Viperidae

\section{INTRODUCTION}

Snakes and Lizards are the most flourished reptiles of the day. Karyological and biochemical data act as a supplement to the morphological approach. Data collected from gross anatomical, karyological and biochemical analysis, when combined, help in revealing valuable insight into the evolution of snakes. Karyologically, snakes are highly conserved and variation is found only at family or subfamily level. They show a narrow range of chromosome number showing a preponderance of species with $2 \mathrm{n}=36$ ( 16 macro- and 20 microchromosomes). Reptilian chromosomes have long been under discussion particularly in relation to the sex determining mechanism (MATTHEY and VAN BRINK 1956) because in reptiles situation is inconsistent showing female heterogamety in many species of snakes (KoBEL 1967; BECAK et al 1962, 1964; SINGH 1972) and apparent digamety in lizards (GoRMAn and AtKins 1966, 1968; GORMAN et al 1967) which is a situation in between male heterogamety of mammals and female heterogamety of birds.

Snakes show a step by step sex chromosome differentiation from morphologically undifferentiated to gross differentiation status i.e. according to the evolutionary status of the family, the sex chromosomes are homomorphic in primitive

Corresponding authors: * neeruom@yahoo.co.in; **gksasan@yahoo.co.in families and well differentiated in highly evolved ones (Ohno 1967; Becak and BecaK 1969). The macrochromosomes are often described as marker chromosomes as these are species specific and individually identifiable (SINGH 1972). Male meiotic cells of reptiles offer good material for karyotypic studies, particularly in species with substantial number of very small chromosomes whose number is often difficult to determine from somatic preparations. The present communication describes the karyotype of four species of Indian snakes viz E. conicus, N. n. naja, V. russelli, and E. carinatus from Jammu region.

\section{MATERIALS AND METHODS}

Live specimens of E. conicus (Family Boidae), $V$. russelli, E. carinatus (Family Viperidae) and $N$. n. naja (Family Elapidae) were collected from natural populations of Jammu region of $\mathrm{J} \& \mathrm{~K}$ state with the help of hand net during the months May to Sept., 2004. In the laboratory they were injected intraperitoneally with $0.9 \%$ colchicine $(1 \mathrm{ml} / 100 \mathrm{gm}$ body weight) for 24 hours prior to dissection. An additional dose of $0.9 \%$ colchicine was given for $3 \mathrm{hrs}$ after dissecting open the anesthetized animal. Both germinal and somatic tissues (bone-marrow, aspired from ribs and spleen) were extracted and hypotenised in $0.9 \%$ sodium citrate for 50 minutes. Hypotenised tissues were then fixed in Carnoys fixative ( 3 methanol: 1 acetic acid) for 30 minutes. Slides were then prepared by 
dabbing and stained in 2\% Giemsa stain. Well spread metaphase complements were photographed, karyotyped and assigned nomenclature as given by LEVAN et al (1964).

\section{RESULTS}

Family Boidae - 1. Eryx conicus - An analysis of 50 well spread metaphase complements from different somatic tissues of one male and two female specimens revealed a diploid count of 34 chromosomes comprising 16 macro- and 18 microchromosomes $(\mathrm{NF}=42)$ (Fig. 1). The macrochromosomes include 8 metacentrics, 2 subtelocentrics and 6 telocentrics. There exists a sharp distinction in size between macro- and microchromosomes and all the microchromosomes are small, dot-like with size ranging from 0.9 micron to 0.3 micron. Among meiotic stages, diakinesis exhibited 8 macro- and 9 microbivalents. The largest macrobivalent carried 3 chiasmata, while the rest macrobivalents possessed 2 chiasmata each (Fig. 2). Due to great condensation and minute size, number of chiasmata in microbivalents was not discernable. The sex chromosomes could not be distinguished in either sex.

Family Elapidae - 2. N. naja naja - The chromosomal analysis has been done from 3 female individuals. A total of 50 metaphase plates from different somatic tissues revealed $2 \mathrm{n}=38$ as the diploid number comprising 16 macro- and 22 microchromosomes $(\mathrm{NF}=50)$ (Fig. 3). Macrochromosomes include 14 metacentrics and 2 submetacentrics. Microchromosomes are small dot-like, their size varies from 0.72 micron to 0.48 micron in length. The sex chromosomes could not be distinguished.

Family Viperidae - 3. Vipera russelli - Based on the study of about 80 well spread metaphase complements of female $V$. russelli, a diploid count of $2 \mathrm{n}=36(\mathrm{NF}=48)$ has been observed comprising of 16 macro- and 20 microchromosomes (Fig. 4). Of the 8 pairs of macrochromosomes, 6 are metacentrics, 1 is subtelocentric and 1 telocentric. The microchromosomes are small dot-like with indistinct morphology and their length ranges from $0.50 \mathrm{mi}$ -

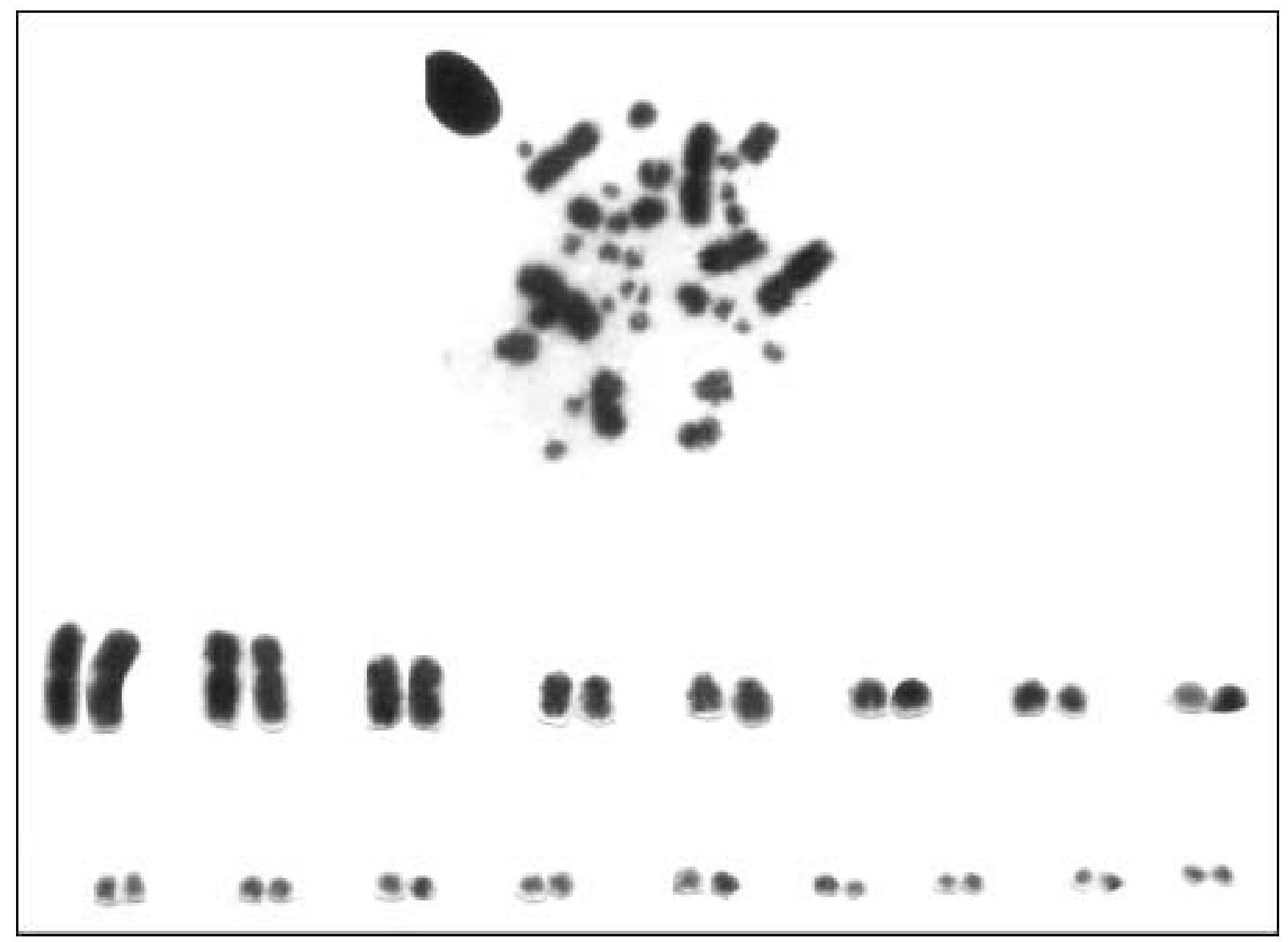

Fig. 1 - Somatic metaphase complement and karyotype of Eryx conicus. 


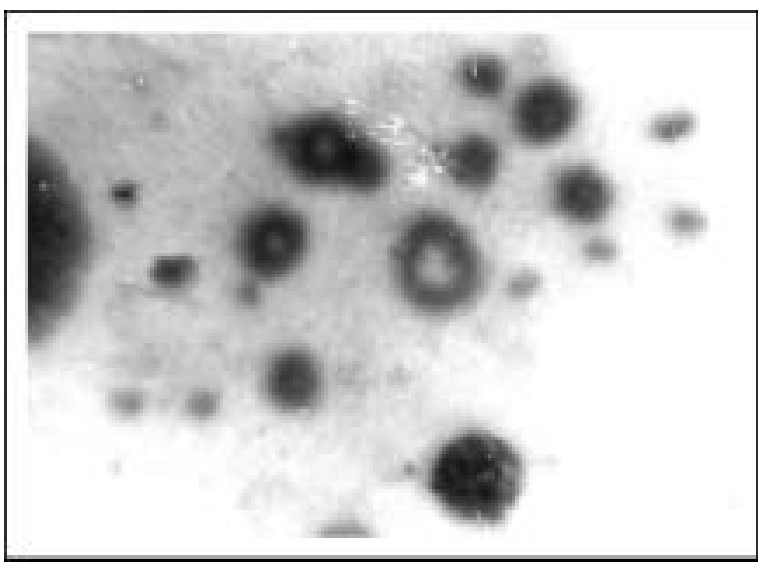

Fig. 2 - Diakinesis of Eryx conicus.

cron to 0.19 micron. The metaphase complements of female revealed a heteromorphic pair of sex chromosomes, a smaller 'W' (submetacentric) and a larger ' $Z$ ' (metacentric). Excluding the length of microchromosomes the ' $\mathrm{Z}$ ' chromosome constitutes $10.6 \%$, while ' $W$ ' constitutes $7.07 \%$ of the length of haploid set. At diplotene 8 macro- and 10 microbivalents have been observed, the larger two bivalents carry 3 chiasmata each, while the rest macrobivalents exhibit 2 chiasmata each. The chiasmata are not distinguishable in microbivalents due to their small size (Fig. 5).

4. Echis carinatus - A study of 50 well spread metaphase complements from different somatic tissues of female E. carinatus exhibited 36 chromosomes $(2 n=36)$ comprising of 16 macro- and 20 microchromosomes (NF=50) (Fig. 6). The macrochromosomes include 5 pairs of metacentrics, 1 pair of submetacentrics, 1 pair of subtelocentrics and a heteromorphic pair of sex chromosomes viz. a larger metacentric ' $Z$ ' and a smaller submetacentric 'W' indicating 'ZW' sex mechanism in female. The ' $Z$ ' chromosome constitutes $6.9 \%$ of the haploid set (excluding the length of microchromosomes). The length of microchromosomes ranges from 0.48 micron to 0.18 micron. Diplotene exhibits 8 macrobivalents, of which $1^{\text {st }}$ and $2^{\text {nd }}$ bivalents carry 3 chiasmata each, while the rest carry 2 chiasmata each (Fig.7). The chiasmata were not distinguishable in microbivalents due to their small size.

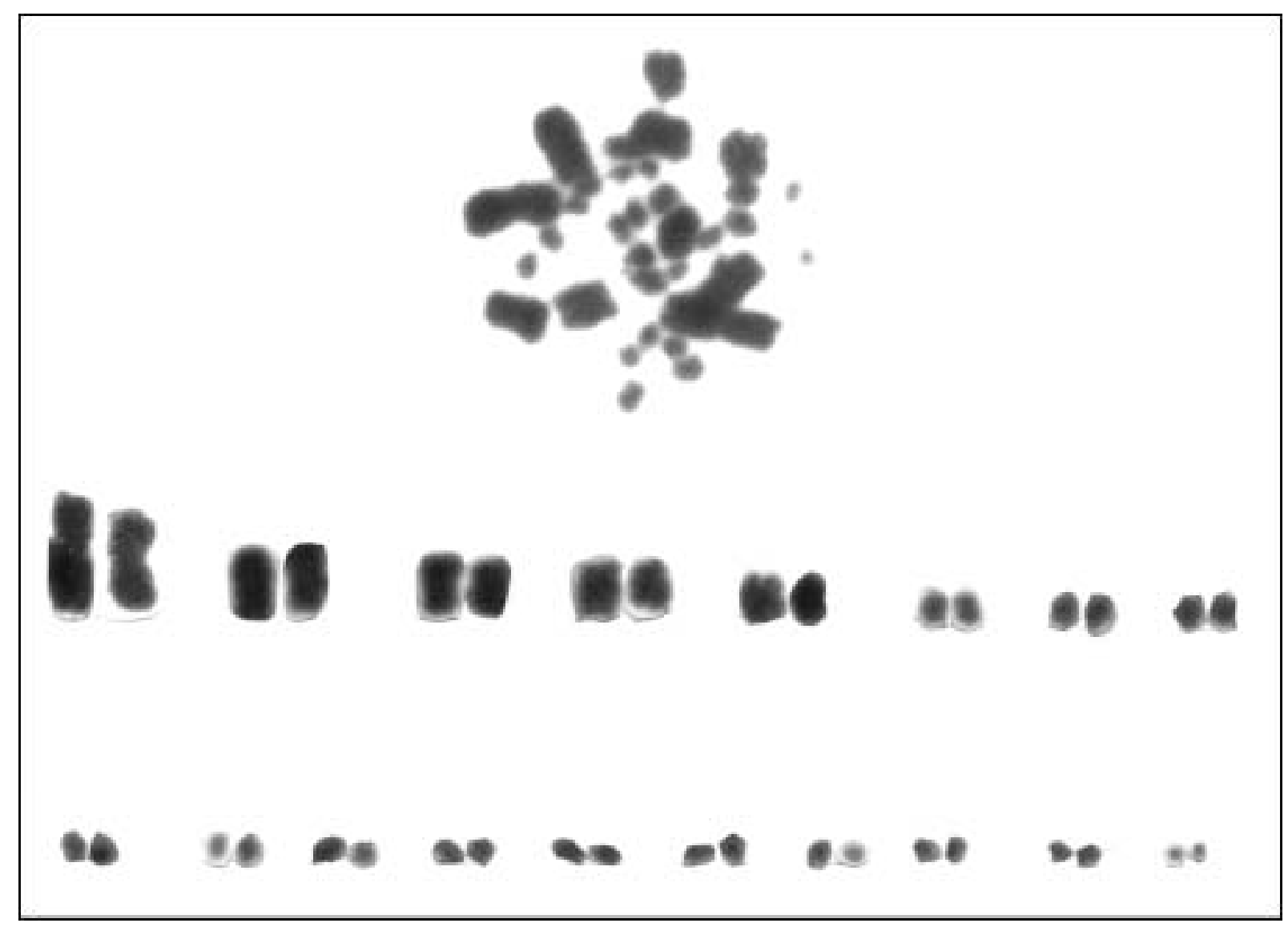

Fig. 3 - Somatic metaphase complement and karyotype of Naja naja naja. 
Table 1 - Morphometric data of macrocomplement of female Eryx conicus

\begin{tabular}{ccccccc}
\hline $\begin{array}{c}\text { Chromosome } \\
\text { pair no. }\end{array}$ & $\begin{array}{c}\text { Mean length } \\
\text { of short arm 'p' }\end{array}$ & $\begin{array}{c}\text { Mean length } \\
\text { of long arm 'q }\end{array}$ & RL\% & $\begin{array}{c}\text { Arm ratio } \\
\mathrm{q} / \mathrm{p}\end{array}$ & $\begin{array}{c}\text { Centromeric } \\
\text { index p/p+q }\end{array}$ & Nomenclature \\
\hline 1 & 1.8 & 1.8 & 18.4 & 1.0 & 0.50 & $\mathrm{~m}$ \\
2 & 1.35 & 1.80 & 16.1 & 1.29 & 0.5 & $\mathrm{~m}$ \\
3 & 1.26 & 1.26 & 12.9 & 1.0 & 0.44 & $\mathrm{~m}$ \\
4 & 0.9 & 0.9 & 9.28 & 1.0 & 0.48 & $\mathrm{~m}$ \\
5 & 0.39 & 1.20 & 8.14 & 1.0 & - & $\mathrm{st}$ \\
6 & - & 0.99 & 5.6 & - & - & $\mathrm{t}$ \\
7 & - & 0.99 & 5.0 & - & - & $\mathrm{t}$ \\
8 & - & 0.99 & 5.0 & - & $\mathrm{t}$ & $\mathrm{t}$ \\
\hline
\end{tabular}

Mean length of haploid macrocomplement $=15.63 \mu$. Mean length of haploid microcomplement $=3.9 \mu$. Total length of haploid set $=19.53 \mu . \% R L$ of haploid macrocomplement and microcomplement is 80.05 and $19.9 \%$ respectively.

Table 2 - Morphometric data of macrocomplement of female Naja naja naja

\begin{tabular}{ccccccc}
\hline $\begin{array}{c}\text { Chromosome } \\
\text { pair no. }\end{array}$ & $\begin{array}{c}\text { Mean length } \\
\text { of short arm 'p' }\end{array}$ & $\begin{array}{c}\text { Mean length } \\
\text { of long arm 'q }\end{array}$ & RL\% & $\begin{array}{c}\text { Arm ratio } \\
\mathrm{q} / \mathrm{p}\end{array}$ & $\begin{array}{c}\text { Centromeric } \\
\text { index p/p+q }\end{array}$ & Nomenclature \\
\hline 1 & 1.83 & 1.86 & 15.89 & 1.0 & 0.5 & $\mathrm{~m}$ \\
2 & 1.26 & 1.26 & 10.76 & 1.0 & 0.5 & $\mathrm{~m}$ \\
3 & 1.2 & 1.2 & 10.2 & 1.0 & 0.5 & $\mathrm{~m}$ \\
4 & 1.05 & 1.05 & 8.2 & 1.6 & 0.37 & $\mathrm{sm}$ \\
5 & 0.72 & 1.2 & 8.9 & 1.0 & 0.5 & $\mathrm{~m}$ \\
6 & 0.72 & 0.72 & 6.16 & 1.0 & 0.5 & $\mathrm{~m}$ \\
7 & 0.72 & 0.72 & 6.16 & 1.0 & 0.5 & $\mathrm{~m}$ \\
8 & 0.72 & 0.72 & 6.16 & 1.0 & 0.5 & $\mathrm{~m}$ \\
\hline
\end{tabular}

Mean length of haploid macrocomplement $=16.98 \mu$. Mean length of haploid microcomplement $=6.42 \mu$. Total length of haploid set $=23.4 \mu . \%$ RL of haploid macrocomplement and microcomplement is $72.5 \% \& 27.4 \%$ respectively.

Table 3 - Morphometric data of macrocomplement of female Vipera russelli

\begin{tabular}{ccccccc}
\hline $\begin{array}{c}\text { Chromosome } \\
\text { pair no. }\end{array}$ & $\begin{array}{c}\text { Mean length } \\
\text { of short arm 'p' }\end{array}$ & $\begin{array}{c}\text { Mean length } \\
\text { of long arm 'q' }\end{array}$ & RL\% & $\begin{array}{c}\text { Arm ratio } \\
\mathrm{q} / \mathrm{p}\end{array}$ & $\begin{array}{c}\text { Centromeric } \\
\text { index p/p+q }\end{array}$ & Nomenclature \\
\hline 1 & 2.55 & 2.53 & 23.2 & 1.0 & 0.50 & $\mathrm{~m}$ \\
2 & 1.75 & 2.4 & 18.9 & 1.3 & 0.42 & $\mathrm{~m}$ \\
3 & 1.47 & 1.8 & 14.9 & 1.2 & 0.44 & $\mathrm{~m}$ \\
4 & 1.14 & 1.2 & 10.65 & 1.05 & 0.48 & $\mathrm{~m}$ \\
5 & 0.90 & 0.99 & 8.63 & 1.1 & 0.47 & $\mathrm{~m}$ \\
6 & 0.41 & 1.21 & 7.39 & 2.95 & -40 & $\mathrm{st}$ \\
7 & - & 1.2 & 5.47 & - & 0.30 & $\mathrm{t}$ \\
$\mathrm{z}$ & 1.14 & 1.2 & 10.6 & 1.05 & 0.36 & $\mathrm{~m}$ \\
$\mathrm{sm}$
\end{tabular}

Mean length of haploid macrocomplement (including one $\mathrm{Z}$ chromosome) $=22.16 \mu$. Mean length of haploid microcomplement= $6.20 \mu$. Total length of haploid set $=28.36 \mu$. \%RL of macrocomplement and microcomplement is $78.13 \%$ and $21.8 \%$ respectively.

Table 4 - Morphometric data of macrocomplement of female Echis carinatus

\begin{tabular}{ccccccr}
\hline $\begin{array}{c}\text { Chromosome } \\
\text { pair no. }\end{array}$ & $\begin{array}{c}\text { Mean length } \\
\text { of short arm 'p' }\end{array}$ & $\begin{array}{c}\text { Mean length } \\
\text { of long arm 'q' }\end{array}$ & RL\% & $\begin{array}{c}\text { Arm ratio } \\
\mathrm{q} / \mathrm{p}\end{array}$ & $\begin{array}{c}\text { Centromeric } \\
\text { index p/p+q }\end{array}$ & Nomenclature \\
\hline 1 & 1.32 & 1.35 & 22.6 & 1.0 & 0.49 & $\mathrm{~m}$ \\
2 & 0.9 & 1.2 & 17.8 & 1.3 & 0.42 & $\mathrm{~m}$ \\
3 & 0.81 & 0.81 & 13.7 & 1.0 & 0.5 & $\mathrm{~m}$ \\
4 & 0.6 & 0.6 & 10.1 & 1.0 & 0.5 & $\mathrm{~m}$ \\
5 & 0.54 & 0.54 & 9.16 & 1.0 & 0.5 & $\mathrm{~m}$ \\
6 & 0.21 & 0.72 & 7.88 & 3.4 & 0.22 & $\mathrm{st}$ \\
7 & 0.3 & 0.6 & 7.63 & 2.0 & 0.33 & $\mathrm{sm}$ \\
$\mathrm{z}$ & 0.6 & 0.69 & 10.9 & 1.1 & 0.46 & $\mathrm{~m}$ \\
$\mathrm{w}$ & 0.2 & 0.62 & 6.9 & 3.1 & 0.24 & $\mathrm{sm}$ \\
\hline
\end{tabular}

Mean length of haploid macrocomplement (including one $\mathrm{Z}$ chromosome) $=11.79 \mu$. Mean length of haploid microcomplement= $4.0 \mu$. Total length of haploid set $=15.79 \mu$. $\%$ RL of macrocomplement and microcomplement is $74.6 \%$ and $25.3 \%$ respectively. 


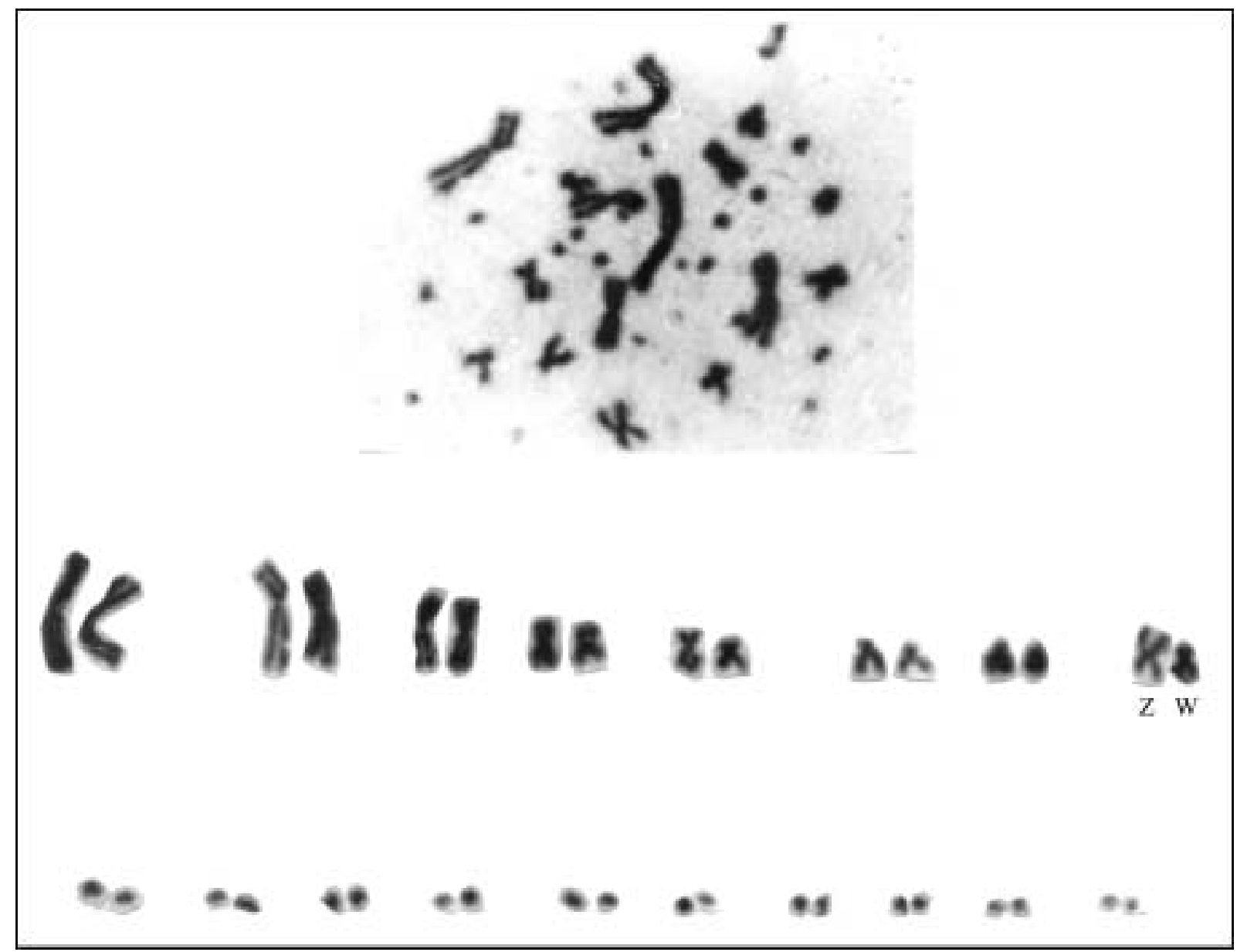

Fig. 4 - Somatic metaphase complement and karyotype of Vipera russelli.

\section{DISCUSSION}

Karyotype, which chromosome number characterizes and morphology is a definite and constant character of each species and exhibits more or less, pronounced changes with different groups. It helps in contributing to our knowledge of the degree of affinity between species belonging to same genus or family or even highest systematic category.

Family Boidae includes primitive non poisonous snakes. Till date only 18 species of this family have been cytologically worked out, of which most species possess $2 \mathrm{n}=36$ ( 16 macro- and $20 \mathrm{mi}$ crochromosomes) excepting genus Eryx which possesses 2 microchromosomes less $(2 \mathrm{n}=34$ with 16 macro- and 18 microchromosomes) than the typical ophidian karyotype of $2 n=36$ (SingH 1972). It can be explained by the fact that convergent karyotypic evolution seems to have occurred in this genus and thus it helps to define Eryx as a distant and specialized genus (SINGH 1972). The

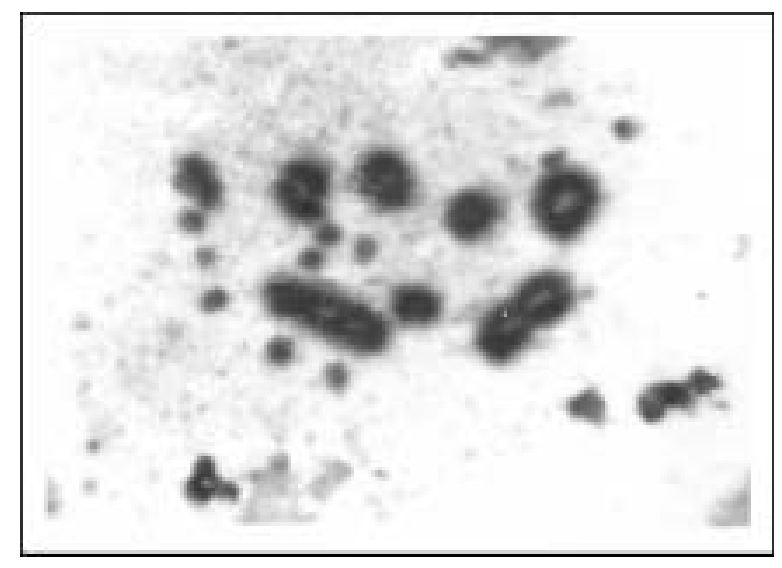

Fig. 5 - Diplotene of Vipera russelli.

karyotype is highly conserved in this family comprising first four metacentric pairs and rest four either telocentric or subtelocentrics. E. conicus has already been worked out by SINGH (1972) and the present data coaccords with that of SingH (1972) excepting that $5^{\text {th }}$ pair is recorded to be 


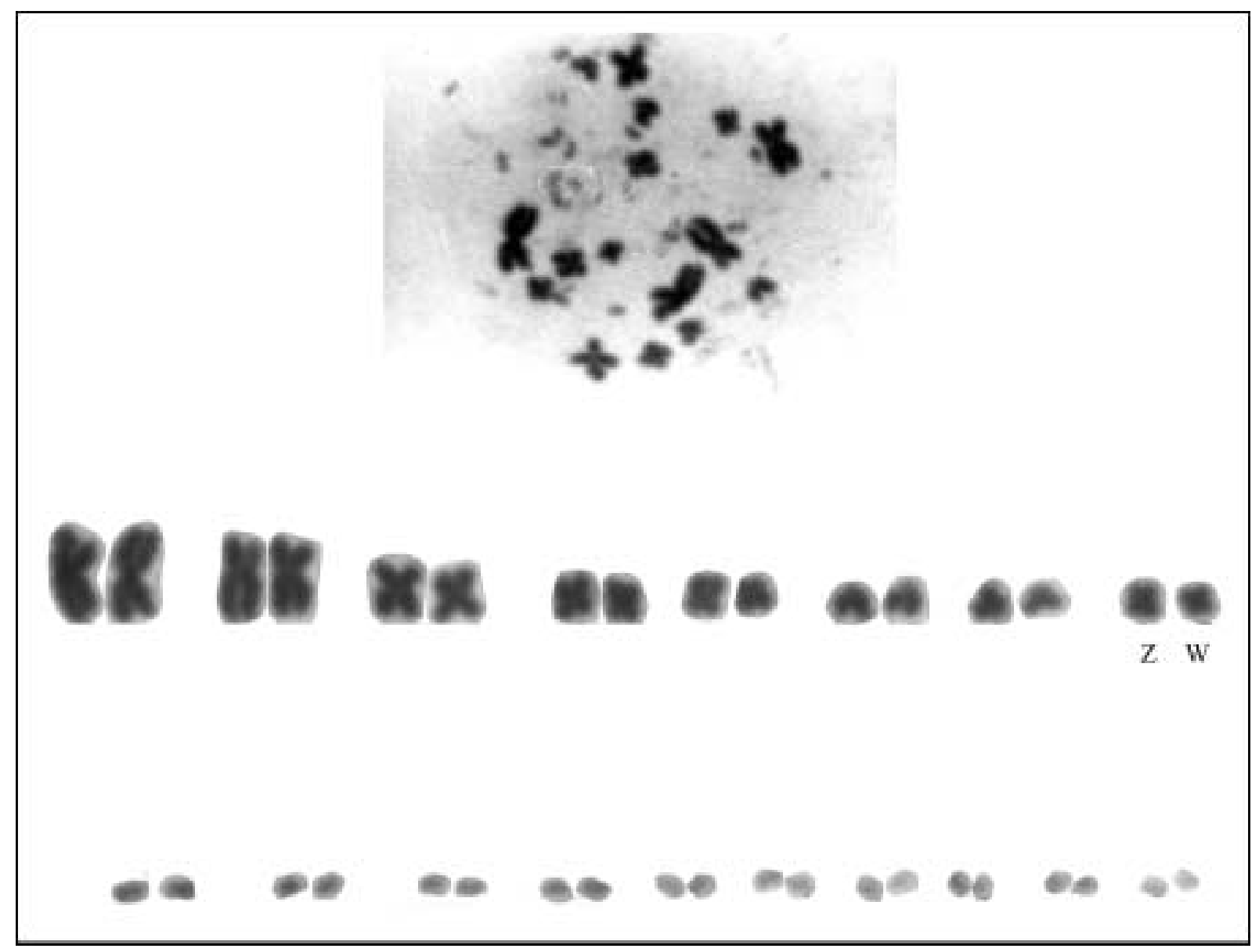

Fig. 6 - Somatic metaphase complement and karyotype of Echis carinatus.

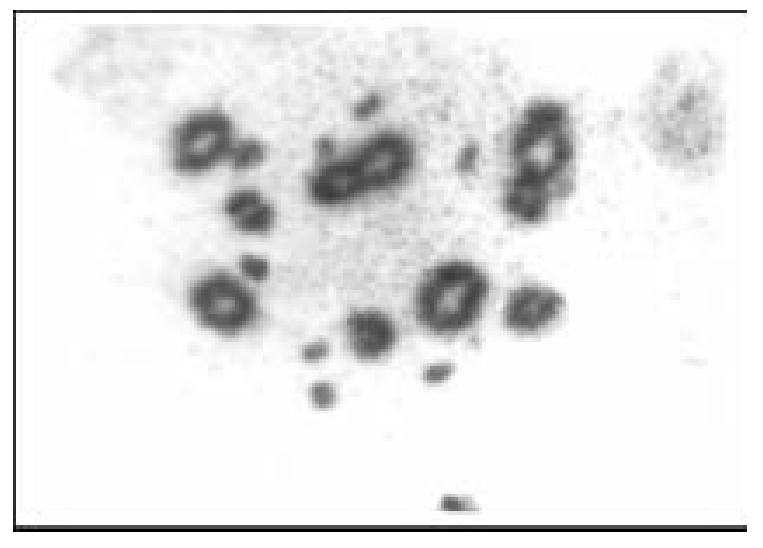

Fig. 7 - Diplotene of Echis carinatus

subtelocentric in the present study and telocentric as reported by SingH (1972). This variation observed in the geographically isolated populations of E. conicus may be attributed to pericentric inversions. E. conicus shows variation in percentage relative length of macro- and microcomplement compared to those reported in other species of the same genus, which is infact the force behind speciation (SINGH 1972), therefore speciation in this genus might have occurred due to translocation involving micro- and macrochromosomes. Family Boidae possesses morphologically undifferentiated sex chromosomes (BECAK and BECAK 1969) as has been observed during present investigation too.

N. n. naja too shows deviation from typical ophidian karyotype ( $2 \mathrm{n}=36$, with 16 macro- and 20 microchromosomes) in having 2 microchromosomes more i.e. $2 \mathrm{n}=38$ (16 macro- and 22 microchromosomes). This species has already been worked out by SINGH (1972) and the present data coaccords with the earlier reports excepting that $4^{\text {th }}$ pair is reported to be subtelocentric in previous report, while it is observed to be submetacentric in the present study which can be attributed to pericentric inversion in this pair. There exists striking similarity within genus Naja i.e. karyotypes of N.n.naja and N. n. kaouthia resemble except that $3^{\text {rd }}$ pair is homomorphic in N.n.naja but heteromorphic sex pair in N. n. kaoutbia. Sex 
chromosomes are morphologically undistinguishable in N. n. naja though it belongs to highly advanced family (Elapidae) where all other members of this family either have well differentiated or multiple sex chromosomes (SINGH 1972).

Family Viperidae consists of 2 subfamilies viz. Crotalinae (with facial pit) and Viperinae (without facial pit) (ZIMMERMAN 1973) and has 240 taxonomically known species worldwide, of which only 4 species are found in J\&K (SAHI 1979). Subfamily Viperinae comprises of 30 taxonomically known species included in 10 genera (DowLING 1959) but cytological data is available for only 8 species. Karyologically this family is highly conserved and homogenous (SINGH 1972) and the species included in this family exhibit a diploid number of $2 \mathrm{n}=36$ ( 16 macro- and 20 microchromosomes) which is infact the modale karyotype of this family. E. carinatus and V. russelli have already been worked out by Singh $(1972 ; 1974)$. The present data coaccords to those of SingH (1972 1974).excepting that in E. carinatus there are reported four pairs of metacentrics, 2 pairs of submetacentrics and 1pair of subtelocentrics (Singh 1974), while present studies revealed 5 pairs of metacentrics, 1 pair of submetacentrics and 1 pair of subtelocentrics. This difference in karyotype of two populations is attributed to pericentric inversions. In both the species (present study) females are heterogametic with well differentiated 'ZW' sex chromosomes whose relative length percentage varies from $9-11 \%$ in ' $Z$ ' chromosome and $5-7 \%$ in 'W' chromosome which substantiate the previous report (SINGH 1972, 1974). Both species belong to different genera and show variation in NF which is attributed to pericentric inversion in $7^{\text {th }}$ pair (telocentric in $V$. russelli and submetacentric in E. carinatus) thus increasing NF by 2 in E. carinatus. This event is followed by translocation of genome fragments since relative length percentage of this pair varies in both species. It may be assumed that speciation might have occurred due to translocation of genome involving macro- and microchromosomes of E. carinatus and $V$. russelli. In addition both species possess highly evolved 'W' i.e. last step of sex chromosome evolution (BECAK and BECAK 1969) where 'W' retains only feminizing genes and hence reduced in size which is substantiated by present study.

\section{REFERENCES}

BECAK W., BECAK M. L, 1969 - Cytotaxonomy and chromosomal evolution in Serpentes. Cytogenetics, 8: 247-262.

Becak W., Becak M. L, and Nazirath H. R. S., 1962 - Karyotypic studies of 2 species of South American Snakes (Boa constrictor amarali and Bothrops jararaca). Cytogenetics, 1:305-313.

Becak W., Becak M. L, Nazirath H. R. S and Ohno S. 1964 - Close karyological kinship between the reptilian suborder Serpentes and the class Aves. Chromosoma (Berl.). 15: 606-617.

Dowling H. G., 1959 - Classification of the Serpentes: A critical Review. Copeia 1:38-52.

Gorman G. C. and Atrin L. 1966 - Chromosomal hateromorphism in some male lizards of the genus Anolis. American Naturalist. 100: 579-583.

Gorman G. C. and AtKin L. 1968 - Confirmation of an X-Y sex determining mechanism in lizards (Anolis). Copeia 1: 159-160.

Gorman G. C., Atkin L. and Holinzer T. 1967 New karyotypic data on fifteen genera of lizards in the family Iguanidae, with a discussion of taxonomic and cytological implications. Cytogenetics, 6: 286299.

KoвeL H.R. 1967 - Morphometrische karyotypanalyse einiger Schlangenarten. Genetica, 38: 1-31.

Levan A., Fredha K., and Sandberg A. A. 1964 Nomenclature for centromeric position on chromosomes. Hereditas, 52: 201-220.

Matthey R. and Van Brink J.M. 1956 - Note preliminaire sur la cytology chromosomique comparee des Cameleone. Rev. Suisse Zool., 63: 241-246.

Онnо S., 1967 - 'Sex chromosome and sex linked genes'. Springer Varlag Berlin, Heidelberg and New York.

SAHI D. N. 1979 - A contribution to the herpetology of JEK state. Ph.D Thesis, Jammu Univ. Jammu J\&K.

SiNGH L., 1972 - Evolution of karyotypes in snakes. Chromosoma (Barl.) 38: 185-236.

SingH L., 1974 - Chromosomes of six species of Indian snakes. Herpetologica 30(4): 419-429.

Zimmerman E. G. and Killipatrick C. W., $1973-$ Karyology of North American Crotaline snakes (Family Viperidae) of the genera Agkistrodon, Sistrurus and Crotalus. Canadian Journal of Genetics and Cytology, 15: 389-395.

Received IV.22.2005; accepted IX.28.2005 